Openings and Retrospectives

\title{
THEORIZING (VACCINE) REFUSAL: Through the Looking Glass
}

\author{
ELISA J. SOBO \\ San Diego State University \\ (D) http:// orcid.org/0000-0002-7711-9873
}

What goes on when people say no? How can we theorize refusal? In this essay I hope to show the value of casting refusal not only as an instance of resistance, but also as distinct from the latter in important ways (picture a Venn diagram). In doing so, I seek to open up space for a dynamic and salutary reading of refusal and, by extension, of resistance itself. I therefore highlight refusal's productivity — not in terms of achieved regime changes or political gains, but of what refusal does for immediate social relations.

My argument starts with the assertion that refusal often begins well before said utterance or act, and extends far beyond the moment of behavioral or verbal proclamation. Moreover, in refusing, resistance - the act of standing against - is not always actually or primarily entailed. Refusal is more about avoidance than active opposition (the characteristic by which most scholars define resistance; see Hollander and Einwohner 2004): in refusal, the overt power contests, class antagonisms, or struggles for liberation or against domination that resistance entails are not necessarily directly implicated. Answering Dimitrios Theodossopoulos's (2014) call to deprimitivize and depathologize how we think about resistant non- 
conformity, the refusal concept that I lay out provides an opening for grappling with the fact that even people who are not outsiders or who have not been excluded can be subversive. It also helps correct for a tendency in resistance studies to position resistant nonconformity on society's (imagined) sidelines because, as I explain, refusal accommodates action taking place directly within the here and now of local social life. Thus, rather than existing as simply a synonym for resistance, the refusal construct can offer, as I hope to show, a complementary albeit partially overlapping (remember Venn) point of view.

This view, or analytic frame, is best understood in light of the emerging anthropology of becoming (e.g., Biehl and Locke 2010), which draws heavily on Gilles Deleuze and Félix Guattari's (1977) explication of potentiality. The anthropology of becoming seeks to remediate for Foucauldian and neo-Marxist views of people as "done to" or "done through." It restores to humanity agentic engagement with life, diverting our attention from foreclosures to openings - from angry nos to happy yeses. Instead of treating subversive discourses and tactics as "windows into the workings of power" (Urla and Helepololei 2014, 434), which has been common in resistance-oriented work, theorizing refusal in terms of becoming allows us to read such subversions in reverse. That is, it enables us to see them not only as signs or symptoms produced in a top-down fashion by existing power structures but also as crucially generative, in and of themselves, of local in-group relations.

Akin to prior process-oriented works, such as those done under the rubrics of performativity and practice theory, an anthropology of becoming gives primacy to desire, for instance focusing on "the ways desires can break open alternative pathways" (Biehl and Locke 2010, 318; but see Sobo 2015a) when individuals and collectivities are excluded from preferred pathways. It highlights how, by means of propositional claims, people challenge stigmatizing classifications and assumed or imposed limitations. Refusers' assertions thus negate outsider or outgroup definitions of the situation and, most importantly in terms of what I want to argue, they reaffirm in-group framings and, thereby, in-group ties. Refusal's immediate focus is not structural reform but the health and vitality of one's immediate social relations.

\section{MY PATH TO THIS OPENING}

I came to this position slowly, through a series of projects beginning (for our purposes) in 2012, at a Waldorf school. Waldorf education is rich in the arts, heavy on experiential learning, and light on summative testing. It has been the 
source recently for a number of mainstream education innovations (e.g., CostelloDougherty 2009). I had been interested in how teachers leveraged Waldorf education's unique pedagogy to promote child health (Sobo 2015a). I also asked how school parents' home health practices aligned with teacher recommendations such as for early bedtimes, a healthful diet, and limited or no media exposure. Vaccination practices were not on my inquiry list, but parents saw them as important and so, in keeping with anthropological convention, I paid attention (Sobo 2015b). In 2014, I began a follow-on project directly focused on vaccine decision-making. However, this second study was not school-sited; it involved a community-based sample (Sobo et al. 2016).

About half of the children in the first project and two-fifths in the second had not gotten all of the vaccinations deemed necessary by the state for kindergarten entry. What stood out to me was that, while in the first study what is popularly glossed as "vaccine refusal" was normative, in the second it was not. Further comparison, between and within groups, revealed vaccine refusal as a complex, multifaceted, processual activity — something that the layperson's use of the phrase vaccine refusal, with its categorical focus on the rejecting aspect, failed to account for.

Such verbal flattening and foreshortening is not unusual in popular talk regarding subversive practices. As Sherry Ortner (1995) has noted, resistance studies, too, can homogenize countercultural discourses or movements, valorizing their subversive potential without examining their inner workings. In reality, resistance is manifold; dominated groups have rich, complex cultural, political, and religious lives that support diverse oppositional activities, with "breaks and splits and incoherencies of consciousness . . . [and even] alternative forms of coherence" (Ortner 1995, 186). Ortner argues that hesitance to explore such things, perhaps for fear of undermining the political aims of study participants, has led to the creation of a superficial and impoverished record that, along with being partial, has stunted the growth and development of resistance-related theory. ${ }^{1}$

It is the same with vaccine refusal: although all parents who are not in full conformity with vaccine recommendations/requirements have traditionally been lumped together as "refusers," great diversity exists within the lot. For one thing, being fully vaccinated entails numerous injections for varied diseases taken over several years' time - but not all refusers refuse the same vaccines or doses. Some skip all shots necessary for kindergarten entrance (which can number in the twenties); some skip one. And parents have diverse reasons for refusing: some worry 
over efficacy; others, side effects; still others, the broader political-economic context in which vaccination is promoted. Moreover, being late for a vaccination or missing vaccinations due to lack of access are not the same as never intending to catch up. ${ }^{2}$

Such variation aside, parents' vaccine refusals were always highly social. To best appreciate this, it is important to understand that what counts as an act of vaccine refusal is an artifact of one's position in relation to the various sociocultural entities of which one is part, and of related affordances and exclusions. To members or practitioners of mainstream culture and society, vaccine refusal signals one's subversive opposition to the status quo. In some ways, at some times, for some vaccine-cautious parents-for instance, those who refuse vaccinations as activists - this equals resistance. Yet as Erica Weiss (2016) notes, refusal need not always involve defiance or action-against. ${ }^{3}$ It can entail quiet abstention instead. More than that: it can be an affiliative act.

In other words, vaccine refusal often serves as a declaration of identification with the social setting of import to the individual. This kind of refusal is more about who one is and with whom one identifies than who one isn't or whom one opposes. While it is the case that vaccine refusal generally entails various important critiques (of the political economy, biomedicine, etc.), vaccine refusal is also, and for some parents more so, a highly social act - an act that, each time it is undertaken, reinforces social belonging by vitalizing community ties. To further grasp this, a quick look at the findings is warranted (for details, see Sobo 2015b and Sobo et al. 2016).

\section{Study One: School Parents}

The average Personal Belief Exemption (PBE; vaccine waiver) rate for California's kindergarteners at the time of the school study was 3 percent for public schools and 5 percent for private (California Department of Public Health, Immunization Branch 2013). The study school's PBE rate was 51 percent.

While some preexisting vaccine caution hitched a ride into the school community along with parents' preference for alternative education, for many members, the tendency toward refusal was intensified or even cultivated from scratch after joining. As one focus-group member summarized: "A lot of people that come [here] have vaccinated their children . . . and then they chose to discontinue." Indeed, younger siblings at the school received notably fewer vaccines than older ones. And by the time participants' children were ready for seventh grade - which for many might represent ten years of community belonging - the 
PBE rate was 71.5 percent. The social fabric of the school served as an incubator, fostering and propagating vaccine caution. Opting out of vaccination was an act of opting in.

It was the case that 49 percent of kindergarteners did not have waivers; they were fully vaccinated. And nearly all of those with waivers had received at least some vaccinations. Still, parents said that the school's culture valorized countercultural child health approaches and supported skepticism regarding governmental and health-care industry interests (which have, in fact, compromised our health previously). So parents with fully vaccinated families remained quiet. Their refusal to refuse went undisclosed for fear of social consequences (e.g., "there's prejudice against mainstream medicine"). Vaccine nondisclosure, in turn, lent strength to the idea that a very large majority of the school community disfavored vaccination. The school's antivaccination reputation was self-reinforcing (Sobo 2015a).

\section{Study Two: Community Parents}

My community-based study questioned vaccine confidence against the backdrop of mainstream digital culture (Sobo et al. 2016). Like the parents just described, vaccine acceptors in the community sample were affected by social factors: they accepted vaccines because of custom or an everyone-does-it-here point of view. In routinized fashion, many were content just to go "with the package" of recommended vaccinations because, as one mother said, it was "a cultural norm."

Most full vaccinators knew surprisingly little about vaccination's mechanism and less about herd immunity, which is "the shared protective effect conferred on unimmunized individuals when a sufficiently large proportion of the population is immunized" (Committee on the Assessment of Studies of Health Outcomes Related to the Recommended Childhood Immunization Schedule 2013, 2). In terms of uptake, this knowledge did not matter anyhow: they vaccinated as part of their parenting routine. A thirty-eight-year-old father with two fully vaccinated preschoolers explained:

For me, it's always been kind of a foregone conclusion that we're doing it. It's just kind of - it's part of the program. I've never had a second thought about not doing it. But I think mostly the decision-I know I'm doing the right thing - is based mostly on previous experience with my parents, [what they] did for me. 
Not to follow tradition — to refuse "the program" — would entail inordinate social risk.

\section{MY VIEW FROM THE CLEARING}

Crucially, all parent discourse regarding vaccine choice-making — whichever position promoted - expressed the desire to belong. Refusal, despite its popularly negative connotations, actually represented a very sociable stance for school parents - as did habitual conformity to vaccine routines for those in the community. Simply lumping refusal into the generic categorical construct of its liberatory counterpart, resistance, would have masked this, eliding how social factors, cultural recommendations, and parents' related identity concerns interacted to support both routine vaccination and its refusal, depending on context.

Further, using the lens of the anthropology of becoming helped me see how vaccine-related subjectivities are always in the making, not least due to the frequency with which vaccinations are offered for young children. Parental confidence in their vaccine decisions must be maintained; claims staked against the grain must be buttressed forcefully and continuously, given extant opposition.

Vaccination-related practices - chatting about a child's vaccine status with friends, self-educating, taking a child in for shots - are significantly social events. They index, as well as validate and reinforce, one's prioritized sociocultural moorings. This holds true even when undertaken alone, or mentally, or otherwise beyond the sight of one's immediately preferred in-group (e.g., in a doctor's office or at the computer late at night). Seen in this light, refusing to be separated from one's in-group constitutes a form of insistence, not resistance. It entails association and becoming, not disaffiliating and being sidelined.

Theorizing refusal in relation to human sociality generates more insight than the negative perspective. Rather than signifying disaffiliation - although it can do that too, as when declining a gift (see McGranahan 2016) — refusal is most productively first appreciated for its generative, affiliative qualities. In this lookingglass light, refusal's primary meaning or aim is revealed as positively prosocial. By rearranging relations (to paraphrase McGranahan) in a way that favors preferred social ties over obligations viewed as irrelevant (if acknowledged) or even as undesirable, refusal is a creative, communion-focused act. It is future-oriented, too: it is a promise to one's child of sustained good health and a vow to one's associates of continued connection. Even the scholars taken to task by Sherry Ortner $(1995,179)$ for refusing to acknowledge "patterns of exploitation and power" internal to subaltern communities likely did so to further refusal's pro- 
social aims: they probably identified with these communities or some common cause (see Simpson 2014). ${ }^{4}$

To refuse vaccine-preventable diseases - to engage in or endorse vaccination - is to proclaim one's social communion with the mainstream. Similarly, to refuse a vaccination is to proclaim one's affiliation with significant others from beyond the mainstream. Like getting a gang tattoo, slipping on a wedding ring, or binge-watching a popular streamed TV show, vaccine refusal entails an act of identification — of opting in — of proclaiming "I belong" and "I share your values." Through vaccine refusal and related expressions of vaccine caution, parents make their commitment to in-group norms clear, thereby ensuring continued good relations with socially valued others (see Brunson 2013; Kahan 2013; Kahan et al. 2012; Sobo 2015b).

Viewing refusal this way entails a paradigm shift of great significance-one in which rejection is neither the primary feature nor the first step in refusing. Key to the affiliative equation infusing this new viewpoint is that rejecting another value set comes after the fact. Selection precedes rejection. The difference this makes is vast both for human subject formation on the ground and for how scholars conceptualize vaccine and similar forms of refusal theoretically.

Vaccine caution and conformity both express and attest to membership, albeit to different groups. Each attests to a group-specific definition of the situation. Nonconformers additionally express an insistence on exceeding official knowledge-power structures - on possibilities beyond the scope that has been delimited for the mainstream (see Biehl and Locke 2010). Acknowledging the proactive way in which refusals embrace and recommend values and norms typifying one's preferred in-group allows us to appreciate an underexamined, undertheorized field of cultural activity. By recognizing that to refuse means to receive and to create-by giving primacy to the positive, salutary, generative pole-we can ask better research questions regarding our social and cultural lives. We can carve a new opening onto human experience: one through which to view and consider human becoming as well as human being, and human doing as well as being done to.

\section{NOTES}

1. Audra Simpson $(2014,97)$ suggests we shift the emphasis away from cross-cultural difference, so that cultures no longer need be presented as "one comprehensive, official story" and internal opposition, struggle, and dissent can be explored.

2. For this and other reasons, many (myself included when writing for vaccine scholars) now label what laypeople call "vaccine refusal" as "vaccine caution" or "vaccine hesitancy." 
3. See Weiss 2016 regarding how overt action-against can be slyly co-opted by the state as, for instance, when refusers are forced to recognize state authority and the default position even when resisting these, and in how refusers willingly make sacrifices in service of the state (i.e., in an effort to change state rules for the good of the nation).

4. Audra Simpson (2014) uses the term ethnographic refusal very differently than Sherry Ortner (1995), for whom refusal serves as a (failed) protective gesture. For Simpson (2014, 34), it is a claim to a "heightened awareness" of the shortcomings of prior ethnographic representations.

\section{REFERENCES}

Biehl, João, and Peter Locke

2010 "Deleuze and the Anthropology of Becoming." Current Anthropology 51, no. 3: 317-51. http://dx.doi.org/10.1086/651466.

Brunson, Emily K.

2013 “The Impact of Social Networks on Parents' Vaccination Decisions.” Pediatrics 131, no. 5: e1397-e1404. http://dx.doi.org/10.1542/peds.2012-2452.

California Department of Public Health, Immunization Branch

2013 “2012-2013 Kindergarten Immunization Assessment Results.” https:// www.cdph.ca.gov/programs/immunize/Pages/ImmunizationLevels.aspx.

Committee on the Assessment of Studies of Health Outcomes Related to the Recommended

Childhood Immunization Schedule

2013 The Childhood Immunization Schedule and Safety: Stakeholder Concerns, Scientific Evidence, and Future Studies. Washington, DC: National Academies Press. http:// www.nap.edu/catalog/13563/the-childhood-immunization-schedule-andsafety-stakeholder-concerns-scientific-evidence.

Costello-Dougherty, Malaika

2009 “Waldorf-Inspired Public Schools Are on the Rise.” Edutopia, August 31. http:// www.edutopia.org/waldorf-public-school-morse.

Deleuze, Gilles, and Félix Guattari

1977 Anti-Oedipus: Capitalism and Schizophrenia. Translated by Robert Hurley, Mark Seem and Helen R. Lane. New York: Viking.

Hollander, Jocelyn A., and Rachel L. Einwohner

2004 “Conceptualizing Resistance." Sociological Forum 19, no. 4: 533-54. http:// dx.doi.org/10.1007/s11206-004-0694-5.

Kahan, Dan M.

2013 “A Risky Science Communication Environment for Vaccines." Science 342, no. 6154: 53-54. http://dx.doi.org/10.1126/science.1245724.

Kahan, Dan M., Ellen Peters, Maggie Wittlin, Paul Slovic, Lisa Larrimore Ouellette,

Donald Braman, and Gregory Mandel

2012 "The Polarizing Impact of Science Literacy and Numeracy on Perceived Climate Change Risks." Nature Climate Change 2: 732-35. http://dx.doi.org/10.1038/ nclimate1547.

McGranahan, Carole

2016 "Refusal and the Gift of Citizenship." Cultural Anthropology 31, no. 3: 33441. http://dx.doi.org/10.14506/ca31.3.03.

Ortner, Sherry B.

1995 "Resistance and the Problem of Ethnographic Refusal." Comparative Studies in Society and History 37, no. 1: 173-93. http://dx.doi.org/10.1017/ S0010417500019587.

Simpson, Audra

2014 Mohawk Interruptus: Political Life Across the Borders of Settler States. Durham, N.C.: Duke University Press. 
Sobo, Elisa J.

2015a "Salutogenic Education? Movement and Whole Child Health in a Waldorf (Steiner) School.” Medical Anthropology Quarterly 29, no. 2: 137-56. http:// dx.doi.org/10.1111/maq.12140.

2015b "Social Cultivation of Vaccine Refusal and Delay among Waldorf (Steiner) School Parents." Medical Anthropology Quarterly 29, no. 3: 381-99. http://dx.doi.org/ $10.1111 /$ maq. 12214.

Sobo, Elisa J., Arianna Huhn, Autumn Sannwald, and Lori Thurman

2016 "Information Curation among Vaccine-Cautious Parents: Web 2.0, Pinterest Thinking, and Pediatric Vaccination Choice.” Medical Anthropology, January 26: 1-18. http://dx.doi.org/10.1080/01459740.2016.1145219.

Theodossopoulos, Dimitrios

2014 “On De-pathologizing Resistance.” History and Anthropology 25, no. 4: 415-30. http://dx.doi.org/10.1080/02757206.2014.933101.

Urla, Jacqueline, and Justin Helepololei

2014 "The Ethnography of Resistance Then and Now: On Thickness and Activist Engagement in the Twenty-First Century." History and Anthropology 25, no. 4:

Weiss, Erica 431-51. http://dx.doi.org/10.1080/02757206.2014.930456.

2016 "Refusal as Act, Refusal as Abstention." Cultural Anthropology 31, no. 3: 35158. http://dx.doi.org/10.14506/ca31.3.05. 